\title{
A CONSTRUCTIONIST APPROACH OF BLENDING SDLC WITH PROJECT-BASED LEARNING
}

\author{
Mohammad A. Rob, University of Houston-Clear Lake, rob@uhcl.edu \\ Farhana Rob, Kaiser Permanente San Jose, Farhana.rob@kp.org
}

\begin{abstract}
Constructionism is an educational philosophy which advocates that learning is most effective when the learner constructs a tangible or meaningful product as part of an educational activity. However, the creation process and the end product must be shared with others to get the full benefit of constructionist learning. This paper tries to address the philosophy of constructionism as it applies to university learning environment where the project-based learning model is used to create a tangible product. Furthermore, we blend the systems development life cycle $(S D L C)$ with the project-based learning to develop a framework that can produce the best possible artifact, fostering a higher order of knowledge to the students. Finally we provide an example that applies our framework.
\end{abstract}

Keywords: Constructionism, SDLC, Project-Based Learning, Systems Development Life Cycle

\section{INTRODUCTION}

Constructionism is an educational philosophy that is inspired by the constructivist perspective of learning proposed by Jean Piaget (Piaget, 1968), who suggested that knowledge is not simply transmitted from teacher to student, but actively created in the mind of the learner. Constructionism is a learning theory initiated by Seymour Papert of the MIT Media Lab, who advocated that learning is most effective when the learner designs or constructs a tangible or meaningful product as part of an educational activity (Papert, 1980). He further suggests that not only the construction process is an integral part of learning for the student, but both the creation process and the end product must be shared with others to receive the full benefit of constructionist learning. Papert's philosophy can be summarized by three learning components: product, collaboration, and sharing.

This paper tries to address the philosophy of constructionism as it applies to higher education, through the implementation of project-based learning that results a significant artifact, and ultimately a higher order of learning. Furthermore, we blend the process of systems development life cycle or SDLC with the project-based learning to develop a framework, which can be employed to produce the best quality artifact - resulting a life-long learning for the students. Finally, we provide an example that employs our framework.

\section{LITERATURE REVIEW}

A significant amount of literature is available on constructivism as compared to constructionism. On the other hand, there are various discussions and misperceptions regarding the two learning theories. In discussing about Constructivism vs. Constructionism, Guzdial (1997) mentions that "I hear them used in so many ways that I often get confused what others mean by them." Piaget's (1968) constructivism is a theory of knowledge that argues that humans generate knowledge and meaning from an interaction between their experiences and ideas. It is important to note that constructivism is not a particular pedagogy. In fact, constructivism is a theory describing how learning happens, regardless of whether learners are using their experiences to understand a lecture or following the instructions to build a model airplane. In both cases, the theory of constructivism suggests that learners build on knowledge based on their experiences. It also addresses how children learn at different stages of their development (Ackermann, 2001). Piaget's theory is most likely to be useful in the early stages of human development, and indeed, an abundance of literature on childhood education aids to support that assumption. Nevertheless, a 
significant amount of pedagogical literature can be found pertaining to upper-level education as well (Hay \& Barab, 2001).

Papert's (1980) constructionism, in contrast, focuses more on the art of learning or learning to learn, and on the significance of creating things while learning (Papert \& Harel, 1991; Ackermann, 2001; Han \& Bhattacharya, 2001; Kafai, 2006; Hoban, Nielsen \& Carceller, 2010). His interest was in how learners engage in a conversation with their own or other people's artifacts, and how these conversations boost self-directed learning, and ultimately facilitate the acquisition of new knowledge. He also stressed the importance of tools, media, and context in human development (Ackermann, 2001; Kafai \& Resnick, 2012). There can be many computing tools and communication media that can be used to enhance learning, and these can be chosen depending on the level of education and subject area. The word context which can be better described as the circumstances that form the setting for an event, statement, or idea, and in terms of which it can be fully understood and assessed, is very important in setting up the learning environment or the classroom. Because of its emphasis on learning through collaboration, building an artifact, as well as the use of tools, media and context, we will focus our discussion on constructionism rather than constructivism.

\section{BACKGROUND \& RESEARCH}

\section{Constructionist View of Learning}

Constructionists assert that learners do not simply get ideas from teachers, but effectively create ideas. This is facilitated through students' involvement in the building of external artifacts that can be reflected on in a collaborative learning environment. Students learn through participation where they make connections between ideas and areas of knowledge facilitated by the teacher through coaching rather than using lectures or step-by-step guidance (Tatham-Maye, 2009). The constructionist teacher takes a mediational role rather than an instructional role, which implies that teaching is replaced by assisting students to reach their goals. Constructionist learning process can be considered as a four-step iterative process (Fei, 2002): Connect: Building new Knowledge, Construct: Learning by Making, Contemplate: Taking time to Reflect, and Continue: Being in Flow.

Even though learning is not limited to the classroom, yet classrooms set the format, tone or approach a teacher takes to convey the knowledge he or she wish to impart on students. Thus it is important to identify the differences between the traditional classroom and the constructionist classroom. In the constructionist classroom, the focus is shifted from the teacher to the students (Classroom Concept, 2016). The classroom is no longer a place where the teacher acts as an expert to pour knowledge to passive students. In this approach, the students are asked to be actively involved in their own process of learning. The teacher acts as a facilitator who coaches, mediates, prompts, and helps students develop and assess their understanding, and thereby promoting their learning in a higher level. The classroom becomes an interactive environment between the teacher and the students.

\section{Project-Based Learning}

Project-based learning (PBL) is a constructionist approach in which a group of students work on a project in a collaborative manner for a certain period of time to produce an outcome, an artifact or a product (Thomas, 2000; Rob, 2006; Rob, 2009, Rob and Etnyre, 2009). The outcome could be an important document, a project plan, an information system, a website, a database, a data warehouse, or anything that the student-group can be proud of. However, we propose a semester-long group project through which students will have enough time to form a group, storm the group, and then collaborate with each other to bring the project towards an end with a significant outcome that culminates all the concepts the teacher is trying to instill in students' minds. A significant outcome also brings satisfaction to students who are the constructors of the product. The teacher still outlines the objectives, sets the guidelines, and then guides the students through the process of planning, analyzing, designing, and constructing the artifact through an interactive approach or having a teacher-student dialog. One important component of the learning 
process is classroom discussion and rework on the artifacts that produce clearer or higher order of knowledge (Rob, 2013). Project-based learning can be used in any course, whether it is programming, database, data warehouse, networking, systems design, or project management.

\section{Systems Development Life Cycle}

The systems development life cycle (SDLC) is a process by which systems analysts, software engineers, and programmers build information systems. It is composed of a number of work phases which are used to plan, design, build, test, and deliver an information system. Like any physical product that is manufactured on an assembly line, an SDLC aims to produce a high quality information system that meets or exceeds customer expectations. In its simplest form, SDLC consists of four phases: planning, analysis, design, and implementation (Dennis, Wixom, and Roth, 2014). In each phase, the understanding of the system requirements becomes clearer and clearer until the end product is completed. SDLC can be applied to any kind of project, whether it is a wedding, a building, a bridge, or a classroom project. It can be used in any course, whether it is a database, web design, programming, networking, data warehouse or project management.

\section{RESEARCH FINDINGS}

\section{The Proposed Framework of Blending Project-Based Learning with SDLC}

Based on the Papert's (1980) theory of learning, which advocates the development of a tangible product in a collaborative learning environment, as well as the four-step learning process forwarded by Fei (2002), we propose a framework that blends project-based learning with SDLC. Development of a product or artifact in a project-based learning environment follows the four-step iterative process: Connect, Construct, Contemplate, and Continue. SDLC is also an iterative process through which a quality product can be developed. We therefore suggest that SDLC approach should be applied in all project-based learning classroom to develop the end product, which in turn will produce a higher order of learning. Figure 1 illustrates our framework. At the heart of the diagram is the product that needs to be developed. A product is an outcome of a project that goes through the steps of planning, analysis, design and implementation.

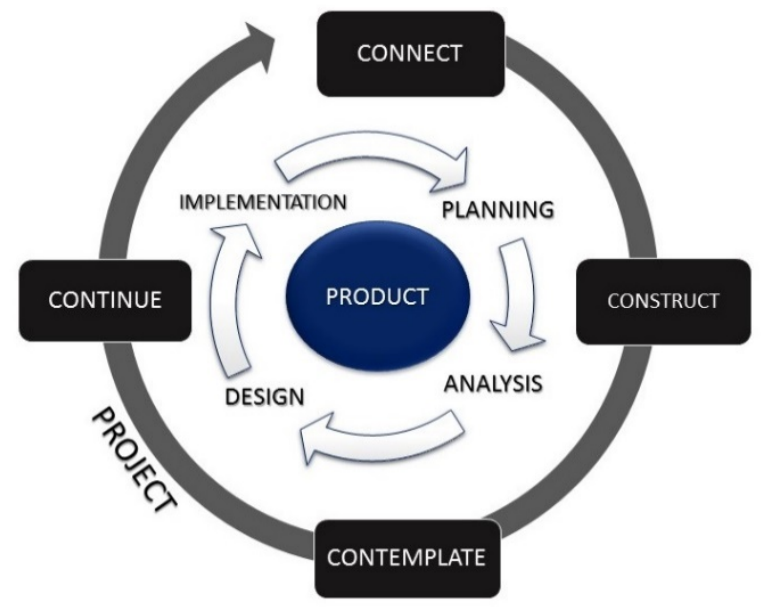

Figure 1. A Framework of Blending Project-Based Learning with SDLC 
In essence, we must make sure that we adapt the four stages of constructionism in a cyclic manner during the semester to develop the end product or artifact. A constructionist teacher takes both a passive and reflective role and designs the classroom accordingly. Ali (2011) provides a systems approach of classroom learning environment. We propose that the group-project must contain multiple presentations during the semester. Also a classroom presentation can be compared with a system that has the mechanisms of inputs, processing, outputs, and feedback. Creating the presentation itself has two major aspects of Papert's (1980) constructionism - the product and collaboration. However, Papert emphasized that learning becomes meaningful when the creation process is shared with others. Presentation of the important work or artifact in the classroom not only provides a mechanism to present the outcome of the constructivist knowledge of the students, but also provides an opportunity of sharing the artifact with others. It fosters classroom discussion including feedbacks from the teacher and fellow students, which lead to the constructionist approach of learning. This is illustrated in Figure 2. Students take the feedback from the class and create an improved artifact - a document or presentation. The ultimate result is an improved knowledge of the subject matter.

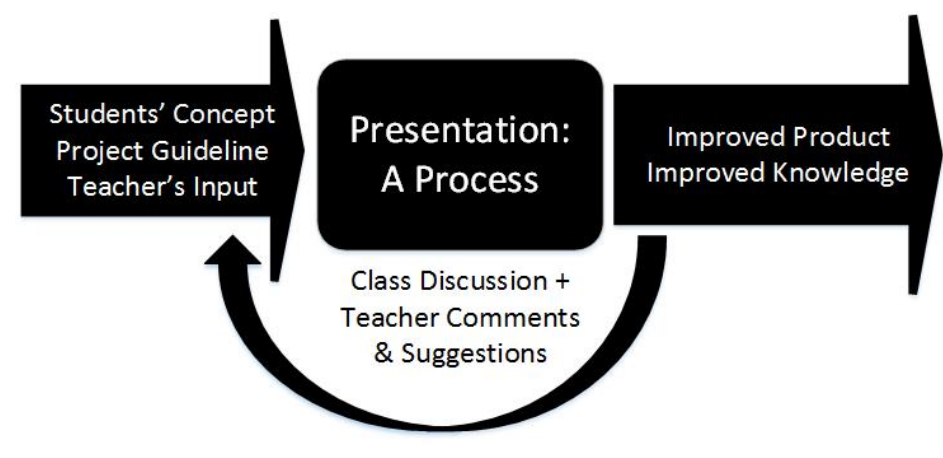

Figure 2. Presentation as a Mechanism of Constructionist Approach of Learning

\section{An Example of Implementing the Framework}

There are many different ways our framework can be implemented in a classroom; however, we will mainly focus on a semester-long group project in which students work in groups in collaboration with each other to produce a significant outcome such as a database, an information system, a website, a project plan, or a final project report. For an example, we will consider the systems Analysis \& Design course that is typically taught in our Management Information Systems (MIS) program. Working on a group project is an essential component of the learning process in the course. Typically the class is divided into multiple groups of 2-3 students per group, and each group may work on an individual project or a single running case found in a typical textbook. We will focus on a single case study for the whole class. The most important part of the learning process in this course is to understand the Data Flow Diagram (DFD) that depicts the flow of data in an information system using four standard components: external entities, processes, data flows, and data stores. Although there are various levels of DFD, for simplicity, we will only consider the 0-level DFD in our discussion, as it is the most important diagram that is used to conceptualize the overall system.

Although a single case problem is assigned to all groups with the necessary concepts of the subject-matter along with the project outlines and guidelines, each group presented a completely different diagram according to their own constructivist view of the problem - some came up with an almost-perfect diagram, some combined DFD concepts with the database, some changed the scope of the problem and included their own business concepts, whereas others diverged completely from the rules and concepts of the data flow diagram. These various types of diagrams for the same problem prompts a significant discussion in the classroom - between the presenters and other students, between the presenters and the teacher, and between the teacher and other students. In most cases, presenters are asked to modify their presentations according to the feedbacks received in the class. Refer to Figure 2 . This iterative 
process of a presentation results a clear understanding of the DFD concept and as well as an improved artifact or product.

Figure 3 shows a 0-level diagram from one of the better groups, before and after the class discussion. Part (a) shows that all data should be stored in a database management system - a concept students learned from the previous database class, without following the role of individual data stores used in the DFDs as discussed in the systems Analysis \& Design Class. This is an example of the constructivist approach of solving the problem. The poor result is due to the application of students' previous knowledge along with the current understanding of the subject matter. Part (b) shows the modified diagram, which includes the necessary data stores and other changes as necessary to reflect the problem scope and DFD rules. This is an example of a constructionist learning process. The improved result is due to class discussion and feedback following the iterative process of presentation as shown in Figure 2.

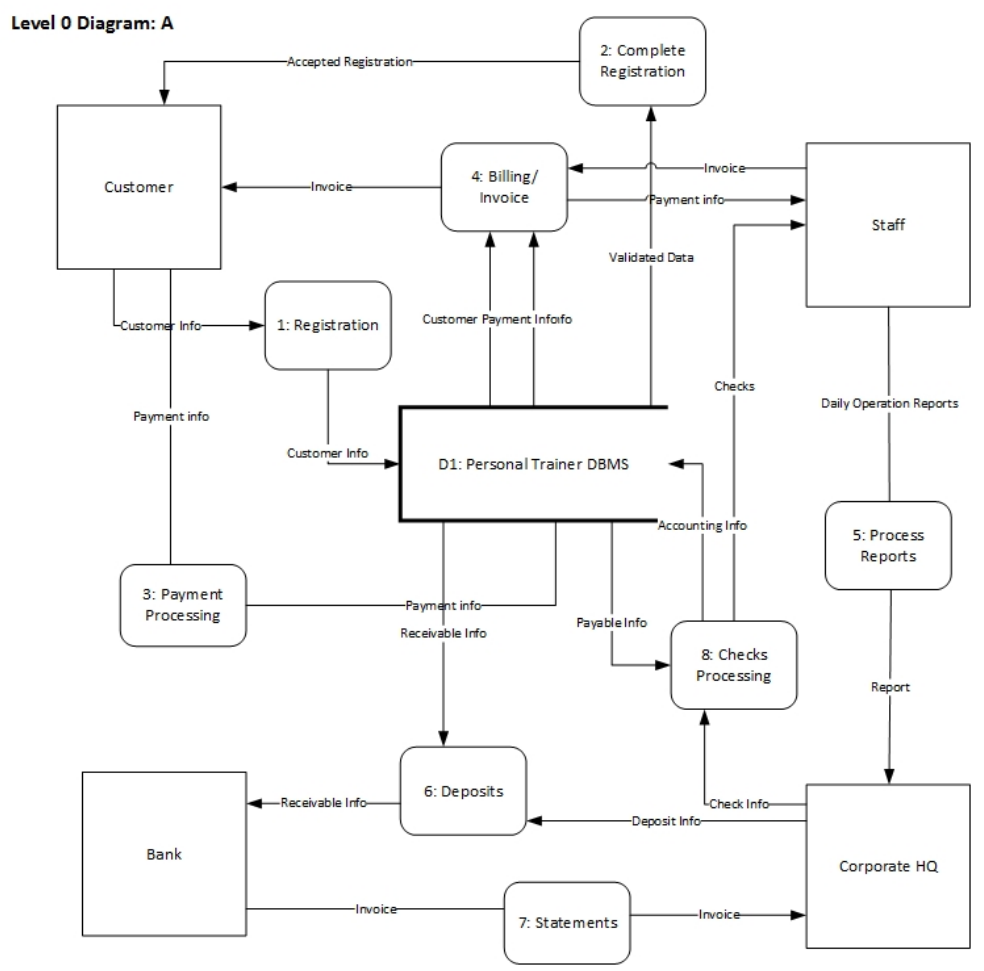




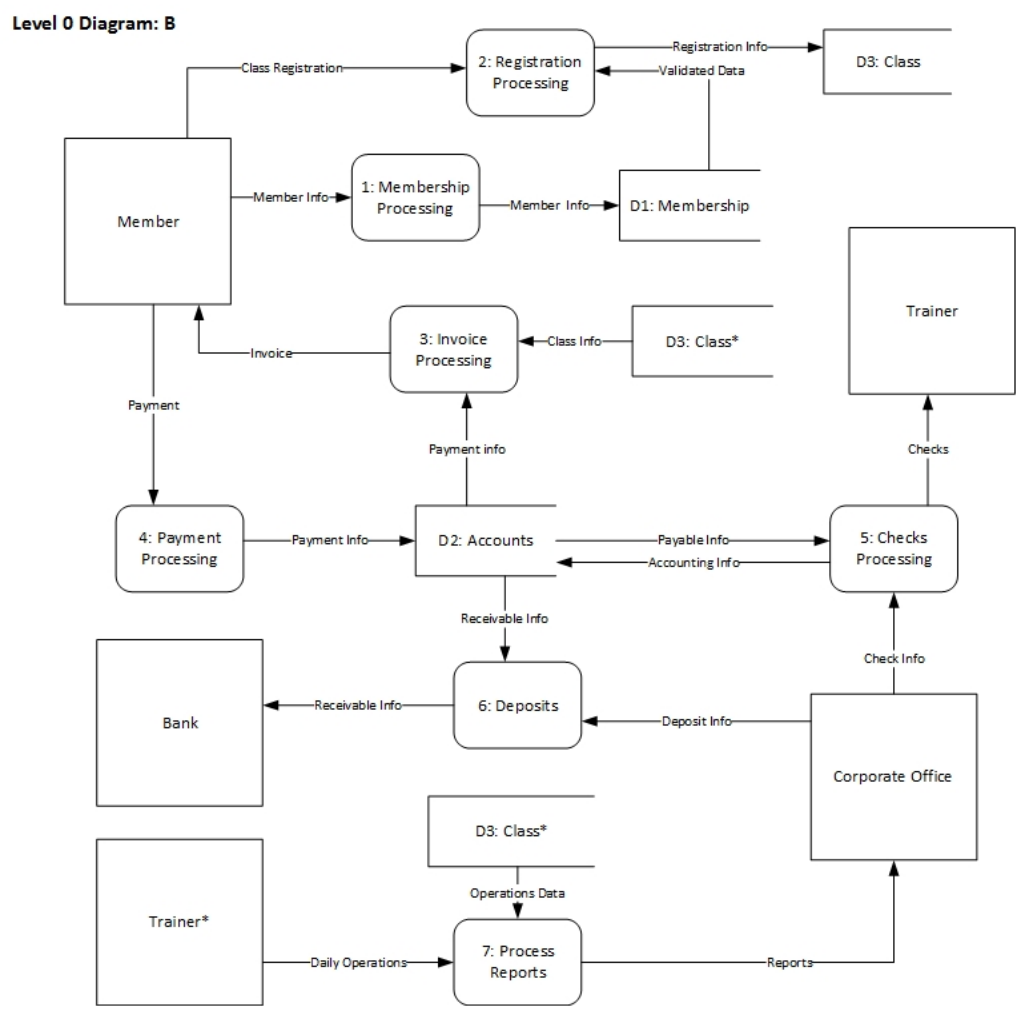

Figure 3. Illustration of (a) Constructivist, and (b) Constructionist Approach of Learning through Data-Flow Diagrams

\section{CONCLUSION}

In conclusion, we have touched briefly on the learning theory of constructionism, which advocates that learning is most effective when the learner designs a tangible and meaningful artifact or product as part of an educational activity. We have argued that constructionism can be applied in a variety of ways, but a semester-long group-project that produces a significant outcome is the most effective approach that embodies constructionist learning. Following the four-step iterative learning process of constructionism as proposed by Fei (2002), we have developed a blended framework which suggests that the development process of project-artifact should follow the phased approach of SDLC that can be applied to any kind of project to develop a quality product. It turn, the process itself provides the best possible knowledge to students on a particular subject, which we have demonstrated through an example that applies our framework in the classroom setting. In today's classroom setting, teaching should be replaced with the active involvement of learning by the students. The most important learning objectives of a course should be repeated to impart knowledge to students' minds. 


\section{REFERENCES}

Ackermann, E. (2001), Piaget's Constructivism, Papert's Constructionism: What's the difference? http://learning.media.mit.edu/content/publications/EA.Piaget\%20_\%20Papert.pdf

Ali, H. (2011), A comparison of cooperative learning and traditional lecture methods in the project management department of a tertiary level institution in Trinidad and Tobago, Caribbean Teacher Scholar, 1(1), pp. 4964.

Classroom Concept (2016), Constructivism as a Paradigm for Teaching and Learning, http://www.thirteen.org/edonline/concept2class/constructivism

Dennis, A., Wixom, B. H. and Roth, R. M. (2014), Systems Analysis and Design, 6th Edition. Wiley Publications, New York.

Fei, T. L. (2002), Learning process in Constructionism in Lego World, http://www.cyberartsweb.org/cpace/ht/thonglipfei/learning.html

Han, S. \& Bhattacharya, K. (2001), Constructionism, Learning by Design, and Project-based Learning. Emerging perspectives on learning, teaching, and technology, Edited by M. Orey.

Hay, K. E. and Barab S. A. (2001), Constructivism in Practice: A Comparison and Contrast of Apprenticeship and Constructionist Learning Environments, The Journal of the Learning Sciences, 10(3), pp. 281-322.

Hoban, G. F., Nielsen, W. S. \& Carceller, C. (2010), Articulating constructionism: Learning science through designing and making "Slowmations" (student-generated animations), In C. Steel, M. Keppell, P. Gerbic \& S. Housego (Eds.), Conference of the Australasian Society for Computers in Learning in Tertiary Education, pp. 433-443.

Kafai, Y. (2006). Constructionism, R. K. Sawyer (Edited), The Cambridge handbook of the learning sciences, Cambridge University Press, pp. 35-46.

Kafai, Y. B. and Resnick, M. edited, (2012), Constructionism in Practice: Designing, Thinking, and Learning in a Digital World, Routledge Publishing.

Guzdial, M. (1997), Constructivism vs. Constructionism, http://guzdial.cc.gatech.edu/Commentary/construct.html.

Papert, S. (1980), Mindstorms: Children, Computers, and Powerful Ideas, Basic Books.

Papert, S. and Harel, I. (1991), Constructionism, Ablex Publishing Corporation.

Piaget, J. (1968), Six Psychological Studies, Vintage Books, New York.

Rob, M. A. (2006), Development of Project Documentation: Key Ingredient in Teaching Systems Analysis and Design, Issues in Information Systems, VII(1), pp. 83-87.

Rob, M. A. (2009), A Framework of Leading towards Learning through Active Engagement of Students, Issues in Information Systems, X(1), pp. 40-50. 


\section{Issues in Information Systems}

Volume 17, Issue II, pp. 115-122, 2016

Rob, M. A. and Etnyre, V. (2009), Project-Based Learning: An Assessment on Team Building across the MIS Curriculum, Journal of International Business Education, 4, pp. 193-208.

Rob, M. A. (2013) Practical Methods of Preparing a Systems Analyst, International Journal of Research in Educational Methodology, 3(3), pp. 359-371.

Tatham-Maye, L. (2009), Constructionism, http://etec.ctlt.ubc.ca/510wiki/Constructionism

Thomas, J. W. (2000), A Review of Research on Project-Based Learning, http://www.bobpearlman.org/BestPractices/PBL_Research.pdf 